\title{
IMPLEMENTING FREE TRADE \\ AREAS: RULES OF ORIGIN \\ AND HIDDEN PROTECTION
}

Kala Krishna

Anne Krueger

Working Paper No. 4983

\section{NATIONAL BUREAU OF ECONOMIC RESEARCH 1050 Massachusetts Avenue \\ Cambridge, MA 02138 \\ January 1995}

This paper is part of NBER's research program in International Trade and Investment. Any opinions expressed are those of the authors and not those of the National Bureau of Economic Research.

(C) 1994 by Kala Krishna and Anne Krueger. All rights reserved. Short sections of text, not to exceed two paragraphs, may be quoted without explicit permission provided that full credit, including $(0)$ notice, is given to the source. 
NBER Working Paper \#4983

January 1995

\title{
IMPLEMENTING FREE TRADE AREAS: RULES OF ORIGIN \\ AND HIDDEN PROTECTION
}

\begin{abstract}
This paper focuses on the effects of rules of origin in Free Trade Areas. We first point out that even rules of origin which are not restrictive, namely those which do not raise costs of production, have very pronounced effects on trade and investment flows. We then look at some different ways of specifying rules of origin (ROOs) under perfect competition. We compare price and cost based ROOs and show that even if they are equivalent in the "long run", they are not equivalent in the short run where capacity constraints can exist. We also show that some kinds of ROOs can be ranked in terms of their implications for producer profits. We also show that welfare is likely to be non monotonic in the restrictiveness of the ROO, so that making a ROO more stringent could raise welfare. Finally, we show that in the presence of imperfect competition, ROOs may raise output and reduce prices as they become more stringent.
\end{abstract}

Kala Krishna

Department of Economics Pennsylvania State University

401 Kern Graduate Building

University Park, PA 16802

and NBER

\author{
Anne Krueger \\ Department of Economics \\ Stanford University \\ Stanford, CA 94305-6072 \\ and NBER
}




\section{INTRODUCTION*}

In recent years, considerable progress has been made in understanding the effects of trade policy, especially when markets are imperfectly competitive. It is now well understood that the same instrument may have different effects under alternative market structures. However, little attention has been focused on the role of implementation. The precise manner of implementing trade restrictions may also alter incentives, resource allocations and results, both when markets are competitive and when they are not. The relative lack of attention paid to the details of implementation has resulted in the neglect of a number of interesting real world phenomena. When these are studied, conventional wisdom on a number of issues is challenged and needs to be rethought.

In this paper we focus on one such area, where market structure and particulars of implementation turn out to be highly important. That is, we focus on the contrasting incentive and resource allocation effects of different rules of origin (ROOs) ${ }^{1}$ within free trade agreements (FTAs). There are, of course, many other areas where the details of implementation are critical.

*We are indebted to Donald David, Robert Feenstra and Will Martin for helpful comments, and to Jan Herin and Bernard Hoekman who provided useful insights in correspondence on an earlier

1 These rules of origin are used to determine whether a good is eligible for preferential treatment or not. 
draft of this paper. These include issues like the effects of different forms of implementing other direct controls such as quotas on imports ${ }^{2}$ or limits on emissions of pollutants or market access requirements to mention a few.

The North American Free Trade Agreement (NAFTA) has focused attention on regional trading arrangements. Many analysts have tended to view NAFTA and other FTA arrangements as being preferential trading arrangements similar to customs unions. And indeed, in some respects they are.

However, ROOs, which are part of both FTAs and customs union agreements, can have significantly different effects under these two arrangements. In a customs union, members have a common external tariff. Therefore, when a ROO is agreed upon, its purpose is simply to determine when members will provide preferential treatment for fellow members. For example, the European Community (EC) has rules governing treatment of imports of semiconductors: if diffusion is undertaken within the Community, then importation to another EC country is dutyfree. If, however, diffusion is undertaken abroad, then the import is treated as having been produced outside the community, and the (common) external tariff applies ${ }^{3}$.

In an FTA, members maintain their own external tariffs. As such, tariffs may differ between member countries. ROOs, therefore, assume a function additional to that under customs

${ }^{2}$ See Krishna and Tan (1993) for one illustration. They analyze the effects of transferable permits versus non transferable ones. They show that contrary to conventional wisdom, transferable permits need not raise more revenue than non transferable ones and that, depending on the weight given to revenues in welfare, transferable permits need not dominate non transferable ones.

${ }^{3}$ ROOs in customs unions bear a strong resemblance to domestic content requirements, often used by developing countries. See below, where these content requirements and their effects are discussed. 
unions: ROOs are established because, in their absence, imports of any particular commodity would enter through the country with the lowest duty on the item in question and be reexported to other countries in the FTA. Without ROOs, an FTA could be highly liberalizing, as the lowest tariff would apply to each category of imports. ${ }^{4}$

However, unlike ROOs in customs unions or domestic content requirements in developing countries, ROOs in an FTA can also serve to export protection! Suppose one FTA producer, say $\mathrm{A}$, is a high cost (relative to non member countries) producer of intermediate goods used in producing a final product which is subject to protection by $\mathrm{A}$ and is exported or exportable by the other partner, B. Then A can impose a ROO on B's assembly of the final product and make it profitable for B's producers to shift their purchases of intermediates from the rest of the world (even if there is a zero tariff on these) to A, in order to satisfy the ROO and realize A's internal (tariff driven) price for the final product. In other words, it can pay producers to buy from a higher cost FTA source than from the rest of the world, in order for them to qualify for preferential treatment on their sales to their FTA partner. ${ }^{5}$ Thus, trade patterns and investment

${ }^{4}$ This statement assumes that transport costs among members of the FTA are not so high as to offset tariff differentials. When transport costs are significant, an FTA could have adverse welfare consequences that a ROO might prevent or reduce. An example, due to Will Martin, illustrates why. Assume that two countries in an FTA have the same transport costs from the rest of the world. Both import the good in question before the FTA. The high tariff country has a $10 \%$ tariff while the partner has a zero tariff. Transport costs are just under $10 \%$ for intra FTA trade. In this situation, without a ROO, all imports will enter through the zero tariff country and are shipped to the partner country. Consumer prices would be essentially unchanged but the high tariff country would get no tariff revenues (which would be dissipated in paying real transport costs). Thus, welfare would be lowered, relative to the status quo, by an FTA with no rules of origin present. Rules of origin which prevented this could result in a welfare improvement relative to the FTA without rules of origin.

${ }^{5}$ See Krueger (1992) for an example with a fixed coefficients technology. 
flows needed to sustain them can be profoundly affected by a FTA.

In what follows, we first provide some background on ROOs, and relate our work to previous work on domestic content requirements and customs unions. Thereafter, we deal with the implications of alternative ROOs in the long and short run, and with different market structures. A final section contains some ideas on future research.

That ROOs may be protectionist does not, of course, prove that they are. Indeed, many may not be. ${ }^{6}$ However, in the NAFTA agreement, ROOs turned out to be a significant source of contention. ROOs for automobiles and apparel were the last items on which agreement was reached. The intensity of U.S. industry pressures for ROOs certainly gave the appearance that the affected industries, especially automobile producers, viewed higher ROOs as in their self interest. That ROOs are regarded as important was reflected not only in industry pressure for them, but in the fact that ROOs occupy 200 pages of the NAFTA agreement.

${ }^{6}$ Will Martin has pointed out in correspondence that a high ROO might reduce trade diversion costs of a preferential trading arrangement and thus be welfare enhancing. 


\section{BACKGROUND}

ROOs can be defined in a variety of different ways. From a legal point of view, there appear to be four alternative criteria. These are (a) requirements in terms of domestic content, (b) requirements in terms of a change in tariff heading $(\mathrm{CTH})$, (c) requirements in terms of specified processes that must be performed within the FTA or CU; and (d) requirements that the product has been "substantially transformed".

However, for our purposes, these criteria are both too broad and too narrow. They are too narrow, we argue below, as some of these categories are analytically similar. They are too broad for two reasons. First, some of the four methods may differ in the details which could be specified in a number of alternative ways which alter their economic effects. For example, domestic content can be defined in terms of value added or in physical terms ${ }^{7}$. Moreover, the required share of value added can be defined in terms of cost or price ${ }^{8}$. For example, NAFTA provides that value added can be calculated in terms of a transaction value (price) method or a net cost method ${ }^{9}$. These differences matter in terms of their incentive effects and therefore their effects on resource allocation. Second, more than one test may need to be met. For example, the Australia-New Zealand Closer Economic Relationship (CER) relies on a 50\% value added standard in conjunction with the requirement that the last process performed in manufacture be

${ }^{7}$ One example of physical content requirements is that in the cigarette industry in Australia. Cigarette manufacturers must meet a domestic content requirement on tobacco leaf use, defined by weight. See Beghin and Lovell (1992, Forthcoming RESTAT) for an empirical analysis of the effects of this requirement.

${ }^{8}$ There are many variations possible: are capital costs included or not? Are intermediate imports from the partner country counted in domestic content or not? How is the origin of inputs determined?

${ }^{9}$ See Palmeter (1993) footnote 10, pg. 12 for more on this. 
in the territory of the exporting member state ${ }^{10}$.

ROOs set in terms of a change in tariff heading are specified in terms of tariff categories. To satisfy origin requirements a product must change its tariff heading in a specified way. However, by making the changes needed more or less extensive, the origin requirement can be made more or less restrictive. For example, in the U.S.- Canada Free Trade Area (FTA), the production of aged cheese from fresh milk does not confer origin ${ }^{11}$ (see footnote 4 of Palmeter (1993) for details.)

Exceptions to rules on changes in tariff headings can also be used for the same purpose, namely to make the origin requirement more restrictive. For example, under NAFTA, transformation from any other chapter ( 2 digit classification level) of the harmonized system, to tomato catsup, chapter 21 , confers origin, except transformation from tomato paste which falls in chapter $20 !^{12}$ (See Palmeter (1993) pg. 4 for details.)

When origin is instead conferred by performing particular steps in the production process, restrictiveness depends entirely on the steps prescribed and the nature of the production technology. In the case of American imports of apparel under NAFTA, the rule is one of "triple transformation". Only if each step of the transformation from raw material to finished garment has been undertaken within the FTA will preferential treatment be given. American textile producers, of course, benefit from this rule. The difference in this and the CTH criterion is only that the CTH criterion is based on some commonly used descriptions such as the tariff code,

\footnotetext{
${ }^{10}$ See Steele and Moulis (1993) for details.

"See Palmeter 1993 fn. 4 for details.

${ }^{12}$ See Palmeter 1993 fn. 4 for details.
} 
while the specified process definition is defined in terms of production processes specific to each industry.

Substantial transformation on the other hand is more loosely defined. In the United States the term "substantial transformation" has come to mean the determination of origin based on common law, reasoning from case to case. It then results in a commodity-specific ROO which falls into one of the earlier three categories. We therefore do not discuss this criterion further.

From an analytical viewpoint the legal classification makes little sense. We choose to categorize ROOs in terms of: (a) content requirement, sub-categorizing them by the particular form of the requirement, or (b) in terms of transformation steps needed to confer origin. We focus on (a) since we have little to say about (b) other than that it must raise costs. ${ }^{13}$

If ROOs specify minimum requirements for domestic value added, they can be defined in different ways. For example, a ROO can be defined as requiring a minimum proportion relative to unit cost of domestic value added. Alternatively, value added domestically can be defined as the price obtained less the value of imported unit intermediate input requirements, with value added share defined relative to price.${ }^{14} \mathrm{~A}$ further variation is to put a minimum value share of FTA unit input requirements relative to price. Since cost information is harder to get than price information, the price based definition is favored on grounds of implementation. Yet the effects of these three variations differ; little work has been done on this issue. Especially with the price definition of value added, since the price of the product is itself endogenous, the

${ }^{13}$ However, note that input decisions in this case are affected only by the absence of tariffs on imports from the partner country and not by a content requirement on their use.

14 This is equivalent to specifying a maximum value share of unit imported inputs relative to price. 
assumptions made in terms of timing and technology turn out to be vital.

From the above description, it is evident that ROOs under FTAs bear a resemblance to the domestic content requirements often imposed by developing countries' governments. Content protection schemes specify requirements on the share of domestic content in production. Failure to meet these requirements results in a penalty tariff on inputs for domestic producers or a penalty tariff on the import of the final good if the final good is imported.

Content protection policies have been previously analyzed in the literature at both a theoretical and empirical level. We focus on the former. Johnson (1971), Corden (1971) contain some of the early work on the subject. McCulloch and Johnson (1973) pointed out that a content protection scheme is basically a proportionally distributed quota as the ability to import foreign inputs depends on the use of domestic inputs. Content protection has been favorably compared to a tariff on inputs in Mussa (1984). The argument given there is that while content protection distorts the input mix, thereby raising costs, costs rise less than under a tariff that leads to the same input mix. The reason is that foreign input prices do not rise in the former case. Mussa (1984) also analyzes the implications for technological progress of such schemes.

Grossman (1981) analyzes physical and value added restrictions on domestic content. He examines the case where not meeting the content requirement results in a penalty tariff on the imported intermediate good, with a focus on the case where the domestic and foreign inputs are perfect substitutes. He points out that while content protection causes substitution towards domestic inputs, it also raises the cost, and hence price, of the final good. The former effect raises the use of domestic inputs while the latter reduces it, since demand for inputs is a derived demand. He demonstrates that a value-added content requirement could reduce value added in 
some cases if domestic and imported intermediates were complementary. He also looks at the effects of having domestic monopoly in the intermediate input and argues that content protection, like a quota, would augment this monopoly power by restricting the ability of competitive foreign suppliers to compete.

Content preference policies, studied by Grossman (1981), allow preferential tariff treatment for imports from less developed countries (LDCs), provided that a minimum content requirement is satisfied by the exporting country. Content preference then, with the preferential tariff set at zero, is similar to the effects of rules of origin specified by a FTA. However, with content preference policies, the content requirement is on the amount of intermediates from the developing country given preference. In implementing FTAs the requirement is on the use of intermediates from the FTA. With ROOs in a FTA, not only does the tariff on the final good fall if the requirement is met (as occurs with content preference), but the price of inputs from the FTA also falls. Input use is thus distorted towards all FTA inputs, and not just towards the inputs of the exporting country as under content preference policies.

Grossman points out that content preference leads to foreign final-goods producers distorting their use of inputs towards those made internally. ${ }^{15}$ This could serve to protect the LDC intermediate good industry from foreign competition, a point similar to that made in Krueger (1992).

More recently, Krishna and Itoh (1986) analyzed the effects of content protection when input suppliers are oligopolistic. They showed that, counter to the case of monopoly, domestic

15 The careful reader of Grossman's paper will notice that there is a problem in the derivation of his Figure 1. The segment EB is not part of the net demand for domestic components. 
input suppliers could lose from such protection even when content requirements are set at freetrade levels. Hollander (1987) looks at the effect of content protection when the final-good market is monopolized by a foreign multinational. De Silanes, Markusen and Rutherford (1993) look at the effect of ROO's in oligopolistic industries. They show that if foreign multinationals rely on imported inputs to a greater degree than do domestic producers, ROO's can reduce output and shift profits to domestic firms. In addition, if output falls, the demand for domestic inputs could also fall.

In the following sections we look at the effects of some different ways of specifying rule of origin. We look for some simple ideas which might be helpful in guiding policy. The simplest setups which can do so are used throughout. We think of our work not as the last word on the subject, but rather as a beginning which could stimulate further work. We begin by looking at models of perfect competition, and then move on to some imperfectly competitive models. 


\section{PERFECT COMPETITION}

In this section we look at the effects of specifying ROOs in terms of price or of cost. ${ }^{16}$ We ask what the effects of this choice might be on the outcome under the FTA. To do so, we must first consider the treatment of costs and analyze the effects of these rules.

A first issue is that of what is included in costs. Does it make a difference whether capital costs are included or not? Here there is a simple idea worth noting. If FTA capital costs are denoted by B and FTA input costs by A, and imported input costs by D, and their sum by $\mathrm{C}$, where $\mathrm{C}=\mathrm{A}+\mathrm{B}+\mathrm{D}$ then it is easy to show that excluding capital costs gives a lower share of FTA inputs than including them. If capital costs are included, the share of FTA costs is given by $(A+B) / C$. If they are excluded, they are given by $A /(C-B)$. Their difference, $((A+B) / C)-(A /(C-B))=B D / C(C-B)>0$. This suggests that any given required share of domestic input use is likely to be harder to satisfy if capital costs are excluded. ${ }^{17}$ The basic intuition is that including capital costs (or any other costs for that matter) raises the numerator by a greater percentage than the denominator, thus raising their ratio, since the numerator is by definition smaller than the denominator. This might help explain why the treatment of interest costs was a bone of contention between the U.S. and Canada and Honda in defining content requirements.

${ }^{16} \mathrm{We}$ ignore the fact that providing appropriate documentation to demonstrate origin can be costly. Herin reports costs to Finnish firms of satisfying EC ROOS for entry of Finnish exports costs firms satisfying ROOs from 1.4 to 5.7 percent of the value of shipments (Herin, P. 7).

${ }^{17}$ The argument is not quite tight since the levels of costs and expenditure on each kind of input will differ in the two cases. Yet it is suggestive. 
Assume that in order to qualify for the FTA treatment, the firm (exporting to the U.S. from Mexico) must show that the cost of all intermediate inputs imported from outside the FTA divided by the total cost of production not exceed a given proportion $(1-\alpha)$. Let there be three kinds of inputs. For simplicity we will assume there is only one input of each kind. First we have non traded inputs, whose price is given by $\mathrm{W}^{\mathrm{N}}$. In addition there are traded inputs produced in the FTA whose price is given by $\mathrm{W}^{\mathrm{T}}$. Finally, there are traded inputs produced outside the FTA whose price is given by $\mathrm{W}^{\mathrm{T}}$.

Assume that the U.S. is a small country so that it does not affect world prices. Also assume that there are constant returns to scale (CRS) in making the final good. Further, assume that Mexican tariffs on this final good, as well as on all imported input goods are zero ${ }^{18}$, and that there is some Mexican production of the final good so that the world price equals the Mexican cost of production.

\subsection{A Cost Based Definition}

Let $C($.$) be the unrestricted cost function and equal the world price. Let R\left(W^{N}, W^{T}, W^{T *}\right.$, $\alpha)$ be the restricted average and marginal cost function for the firm ${ }^{19}$. It is the value function for the cost minimization problem faced by the Mexican firm confronted by the restriction that the value of inputs used from within the FTA be at least a minimum share, $\alpha$, of costs. This problem is set up and analyzed in Section A.1 in the Appendix. Two results from there are

${ }^{18}$ By assuming that there are no tariffs on all inputs even before the FTA we are abstracting from the effects of changes in tariffs on inputs from the partner country due to the FTA.

${ }^{19}$ Our notation in the future suppresses the price of inputs, including them in the "." or suppressing them totally. 
worth pointing out. First, that the value added constraint acts like a tax on the use of $\mathrm{T}^{*}$ and a subsidy at the same rate on $\mathrm{N}$ and $\mathrm{T}$. In this way the FTA acts to export protection. Second, that the value added constraint does not affect the ratio of the marginal products of $\mathrm{N}$ and $\mathrm{T}$.

The firm has the choice of accepting the restriction and obtaining $\mathrm{P}^{\mathrm{US}}-\mathrm{R}(., \alpha)$, or ignoring it, and getting $\mathrm{P}^{\mathrm{US}}-\mathrm{C}(.)(1+t)^{20}$. It chooses the option with the higher payoff . Hence, if $R(., \alpha)<C().(1+t)$, it chooses to accept the restriction. If the converse is true, it does not. Since $R(., \alpha)$ is increasing in $\alpha$ and for low enough levels of $\alpha, R(., \alpha)<C().(1+t)$, the relationship between $R($.$) and C().(1+t)$ is as shown in Figure 1. Therefore, if $\alpha$ is below $\alpha_{1}$ in Figure 1 , then the value-added constraint is not binding and $R(., \alpha)=C($.$) . In this case the$ creation of an FTA will result in the effective lowering of U.S. tariffs on the final good to zero and the U.S. price of the final good will equal the world price which equals the Mexican price. All imports will be produced in Mexico. U.S. welfare must increase in this region, as the consumer surplus gain exceeds the tariff revenue loss.

If the constraint on value added binds, that is $\alpha>\alpha_{1}$, and it is worthwhile accepting the value-added constraint, then the U.S. price equals the restricted cost function $R(., \alpha)$ which exceeds the price in Mexico and the world price. Again, all imports come from Mexico. In this region, U.S. welfare could fall as the gain in consumer surplus can fall short of the loss in tariff revenues. If $\alpha$ is so high that it is not worth accepting the value-added restriction, that is, $\alpha>$ $\alpha_{2}$, the FTA has no effect on the U.S. price which equals $C().(1+t)$. Welfare is also unaffected, relative to the absence of an FTA.

To summarize, the FTA need not equalize the price of the good within the FTA, and an

${ }^{20}$ We assume throughout that tariffs are levied on cost which here equals the FOB price. 
FTA can have drastic effects on trade patterns as outlined above. Mexico can shift the source of inputs away from the low cost supplier even though there is no Mexican tariff. In addition, the investment flows into Mexico needed to enable it to serve the entire U.S. market are likely to be substantial. Also, U.S. welfare is not monotonic in the restrictiveness of the ROO. ROOs could raise U.S. welfare compared to the absence of an FTA, as long as they are not too restrictive.

However, the effect on the U.S. price depends on factors such as the time period in question: in the short run constant returns to scale are unlikely to prevail and investment flows do not materialize. Thus in the short run, as opposed to the long run where costs are constant, all imports are not going to come from Mexico. In the short run, output in Mexico will expand, but as it does, Mexican marginal costs rise choking off supply. Assuming there is no change in the world price and given that Mexico cannot meet all of U.S. demand, the U.S. price will be unchanged. All that will happen is a reallocation of imports from the rest of the world and production in the U.S. to Mexico, causing a reduction in U.S. welfare arising from the loss in tariff revenues. In the longer run, investment will flow into Mexico, leading to the long-run effects outlined above, assuming no effect on world prices and the price of inputs in Mexico.

These results are in sharp contrast to those which would prevail in the absence of any ROO's. In the absence of transport costs and under the same assumptions as made above, welfare would have to rise in the U.S. due to the FTA, as the gain in consumer surplus would outweigh the loss in tariff revenue. However, production in Mexico need not be affected. 


\subsection{A Price Based Definition.}

Assume that in order to qualify for the FTA treatment, the firm (exporting to the U.S. from Mexico) must show that the U.S. price, less the cost of all intermediate inputs imported from outside the FTA divided by the U.S. price exceeds a given proportion " $\alpha$ ". We will be assuming that before the FTA, the U.S. price exceeds the world price because of a tariff on the final good. If the good is also produced in the U.S. under CRS there must be tariffs on imported inputs or differences in other input costs which make the domestic cost equal to the tariff ridden price. We keep the same notation as in the previous subsection.

Let $\mathrm{R}\left(\mathrm{W}^{\mathrm{N}}, \mathrm{W}^{\mathrm{T}}, \mathrm{W}^{\mathrm{T}^{*}}, \alpha, \mathrm{P}^{\mathrm{US}}\right)$ be the restricted unit cost function for the firm. It is the value function for the cost minimization problem for the Mexican firm, which faces a given U.S. price and is confronted by this value added restriction. This problem is set up and analyzed in Section A.2 in the Appendix.

Let subscripts denote partial derivatives from here on. Note also that by the envelope theorem:

$$
\begin{aligned}
\mathrm{R}_{\mathrm{pus}}(\cdot) & =-\lambda(1-\alpha) \\
<0 & \text { for all } \alpha \in[0,1]
\end{aligned}
$$

Thus, the restricted cost function shifts downward for all $\alpha$ as the U.S. price rises. This makes intuitive sense as raising the U.S. price makes the constraint on value added easier to meet. In addition:

$$
R_{\alpha}(.)=\lambda P^{U S}>0
$$

Thus, an increase in the required value-added share required raises costs of production as 
expected, as long as the constraint is binding.

The Mexican firm can choose to accept the constraint and get PUS $-\mathbf{R}(\cdot)$, or not accept it and pay the tariff to get $\mathrm{P}^{\mathrm{US}}-\mathrm{C}(\cdot)(1+\mathrm{t})$. If

$$
R(\cdot)<C(\cdot)(1+t)
$$

it is preferable to accept the restriction and avoid the tariff. If

$$
R(\cdot)>C(\cdot)(1+t)
$$

it is preferable to accept the tariff. In other words, the restriction is accepted if the restricted cost function lies below the tariff inclusive import price.

If $\alpha$ is low enough, the restriction on value added will not be binding and the restricted cost function, $R(\cdot)$ will be identical with the unrestricted one, $C(\cdot)$. As $\alpha$ rises, the restriction becomes binding and $R(\cdot)$ exceeds $C(\cdot)$. Finally, as $\alpha$ rises further, $R($.$) exceeds$ $C().(1+t)$. This progression is depicted in Figure 2. For a given $P^{u s}$, since $R($.$) is increasing$ in $\alpha$, the firm will choose to accept the value added restriction if $\alpha$ is low and not accept it if $\alpha$ is high. Where the switchover points occur depends on the level of $\mathrm{P}^{\mathrm{US}}$.

However, $\mathrm{P} U \mathrm{~S}$ is itself endogenous. As the U.S. price rises R(.) falls as shown in Figure 2. This makes the point at which the value-added constraint becomes binding rise as well. Note $\alpha_{2}$ exceeds $\alpha_{1}$ since an increase in the U.S. price reduces the R(.) function for all levels of $\alpha$. Thus, we need to specify the effect of $\alpha$ on the U.S. price to proceed further. We will denote this function by $\mathrm{P}^{\mathrm{US}}(\alpha)$. Many different treatments are possible here, corresponding to different assumptions on the technological and timing side. One set of assumptions consistent with the 
approach so far is elucidated below.

Assume, as before, that the U.S. is a small country so that it does not affect world prices. Also assume that there are CRS everywhere and that factor prices are fixed, as this is a partial equilibrium framework. Assume that Mexican tariffs on this final good as well as on the imported input good are zero, and that there is some Mexican production of the final good so that the world price equals the Mexican cost of production. Our assumptions so far ensure that Mexico has the ability to serve all U.S. demand should it wish to do so.

Due to the FTA, the U.S. price always equals the lower of the world price plus U.S tariffs and restricted unit costs from Mexico. Thus, even though the U.S. has protection, its domestic price can equal the world price if Mexico can produce at a cost equal to the world price. Given our assumptions, Mexico can do so if the value-added constraint is not binding. Therefore, let us begin by assuming that the U.S price is the world price, and see when this assumption is met. If $\alpha$ is very low, below $\alpha_{1}$ in Figure 2, then the value-added constraint is not binding, assuming the U.S. price equals the world price, and so the U.S. price will in fact equal the world price in this region. In this case, the creation of an FTA will result in the effective lowering of U.S. tariffs on the final good to zero, and the U.S. price of the final good will equal the world price. All imports to the U.S. of the final good will come from Mexico, and by assumption this level of production is possible using a CRS technology.

What if the constraint on value added binds? Again, the U.S. price equals the lower of the world price plus U.S. tariffs and the restricted unit cost from Mexico. Start from where the constraint just becomes binding, $\alpha_{1}$, and increase $\alpha$. This raises the restricted cost and hence U.S. price, as the U.S. price equals the restricted cost function $R\left(., \alpha, P^{U S}\right)$. Since we assume 
that the U.S. is a small country and since we have CRS, all trade will still go through Mexico. Then if $\mathrm{P}^{\mathrm{US}}$ remained unchanged at the world price the constraint would bite, so that PUS would rise. How far would it have to rise? Until $\mathrm{P}^{\mathrm{US}}=\mathrm{R}\left(\cdot, \alpha, \mathrm{P}^{\mathrm{US}}\right)$ assuming that Mexico has the resources to satisfy the entire U.S. market. Differentiating the above equality gives $\mathrm{dP}^{\mathrm{US}}=\mathrm{R}_{\mathrm{pus}}(.) \mathrm{dP} \mathrm{PS}^{\mathrm{us}}+\mathrm{R}_{\alpha}(.) \mathrm{d} \alpha$ implying $\frac{\mathrm{dP}^{\mathrm{US}}(\alpha)}{\mathrm{d} \alpha}=\frac{\mathrm{R}_{\alpha}(.)}{1-\mathrm{R}_{\mathrm{pus}}(.)}>0$. Thus, increasing $\alpha$ would raise $\mathrm{P}^{\mathrm{us}}$.

Since in this region $\mathrm{R}\left(., \alpha, \mathrm{P}^{\mathrm{US}}\right)=\mathrm{P}^{\mathrm{US}}$, it is clear that the total derivative of $\mathrm{R}($.$) ,$ accounting for the fact that $\mathrm{P}^{\mathrm{US}}$ is endogenous, equals that of $\mathrm{P}^{\mathrm{US}}(\alpha)$ with respect to $\alpha$ :

$$
\begin{aligned}
\frac{\mathrm{dR}(., \alpha, \mathrm{Pus}(\alpha))}{\mathrm{d} \alpha} & =\mathrm{R}_{\mathrm{pus}}(.) \frac{\mathrm{dP}}{\mathrm{d} \alpha}+\mathrm{R}_{\alpha}(.) \\
& =\mathrm{R}_{\mathrm{pus}}(.)\left(\frac{\mathrm{R}_{\alpha}(.)}{1-\mathrm{R}_{\mathrm{pus}}(.)}\right)+\mathrm{R}_{\alpha}(.) \\
& =\mathrm{R}_{\alpha}(.)\left[\frac{\mathrm{R}_{\mathrm{pus}}(.)+1-\mathrm{R}_{\mathrm{pus}}(.)}{1-\mathrm{R}_{\mathrm{pus}}(.)}\right] \\
& =\mathrm{R}_{\alpha}(.)\left[\frac{1}{1-\mathrm{R}_{\mathrm{pus}}(.)}\right]
\end{aligned}
$$

Note that the slope of $\mathrm{P}^{\mathrm{us}}(\alpha)$ is less than that of $\mathrm{R}\left(., \alpha, \mathrm{P}^{\mathrm{US}}\right)$ for a fixed U.S. price, but remains upward sloping [as depicted in Figure 2]. Hence for $\alpha$ between $\alpha_{1}$ and $\alpha_{3}$, PUs rises as $\alpha$ rises. When $\alpha$ has risen so much that $R\left(; \alpha, P^{W}(1+t)\right)=P^{W}(1+t)$, the firms will stop accepting the value-added restriction, and the FTA will not affect the domestic price in the U.S. at all! Thus, the price in the U.S. is $\mathrm{C}(\cdot)$ in Region 1 in Figure 2 and equals $\mathrm{P}^{\mathrm{US}}(\alpha)$ defined above in Region 2. It equals $C().(1+t)$ in Region 3 since the U.S. price cannot exceed the world 
price inclusive of the tariff on the final good.

Again, the same points made earlier where cost based restrictions were discussed are worth noting. The FTA need not equalize prices in Mexico and the U.S. and can have dramatic implications for trade patterns and investment flows in Regions 1 and 2. It has no impact in Region 3.

What can we say about the price based versus cost based definitions? From the derivations so far in sections A.1 and A.2 in the Appendix, the two appear to have different effects as the programs look quite different. However, we argue that they do not differ in the long run under certain conditions. But, they do differ in the short run in the presence of capacity constraints. Consider the two programs below:

\section{Program 1:}

Minimize $\mathrm{W}^{\mathrm{N}} \mathrm{a}^{\mathrm{N}}+\mathrm{W}^{\mathrm{T}} \mathrm{a}^{\mathrm{T}}+\mathrm{W}^{\mathrm{T}^{*}} \mathrm{a}^{\mathrm{T}}$ subject to

$$
\begin{aligned}
& \frac{P^{U S}-W^{T *} a^{T *}}{P^{U S}} \geq \alpha \\
& F\left(a^{N}, a^{T}, a^{T y}\right) \geq 1 .
\end{aligned}
$$

Let the value function for the problem be denoted by $R\left(\alpha, \mathrm{P}^{\mathrm{US}}\right)$.

\section{Program 2:}

Minimize $W^{N} a^{N}+W^{T} a^{T}+W^{T^{*}} a^{T^{*}}$ subject to 


$$
\begin{gathered}
\frac{\mathrm{W}^{N} \mathrm{a}^{N}+\mathrm{W}^{\mathrm{T}} \mathrm{a}^{\mathrm{T}}}{\mathrm{W}^{\mathrm{N}} \mathrm{a}^{N}+\mathrm{W}^{\mathrm{T}} \mathrm{a}^{\mathrm{T}}+\mathrm{W}^{\mathrm{T}} \mathrm{a}^{\mathrm{T}}} \geq \alpha \\
\mathrm{F}\left(\mathrm{a}^{\mathrm{N}}, \mathrm{a}^{\mathrm{T}}, \mathrm{a}^{\mathrm{T}}\right) \geq 1 .
\end{gathered}
$$

Let the value function for this problem be denoted by $C(\alpha)$.

We ask what the relationship is between $R(\alpha, C(\alpha))$ and $C(\alpha)$. That is, what can we say about the value function for Program 1 when $P^{U S}=C(\alpha)$ and that of Program 2 when the domestic content requirement is common at share $\alpha$ ?

Let the solution values of $\mathrm{a}^{\mathrm{N}}, \mathrm{a}^{\mathrm{T}}, \mathrm{a}^{\mathrm{T}^{*}}$ for Program 1 be denoted by the Vector $\mathrm{A}^{1}(\alpha)=$ $\left[\begin{array}{l}\mathrm{a}^{\mathrm{N} 1}(\alpha) \\ \mathrm{a}^{\mathrm{T} 1}(\alpha) \\ \mathrm{a}^{\mathrm{T}+1}(\alpha)\end{array}\right]$

Let $R(\alpha, C(\alpha))$ be the corresponding value function.

Similarly, let the Vector $A^{2}(\alpha)=\left[\begin{array}{l}a^{n^{2}}(\alpha) \\ a^{12}(\alpha) \\ a^{T 2}(\alpha)\end{array}\right]$ denote the solution values of $a^{N}, a^{T}, a^{T^{*}}$ for

Program 2. Let $C(\alpha)$ be the corresponding value function. We can show that the following relationships hold.

Lemma 1: $R(\alpha, C(\alpha)) \leq C(\alpha)$ 
Proof: Since $\frac{C(\alpha)-W^{T *} a^{T / 2}(\alpha)}{C(\alpha)} \geq \alpha$, the Vector $A^{2}(\alpha)$ is feasible for Problem 1. Thus, $R(\alpha$, $C(\alpha)) \leq C(\alpha)$ for all $\alpha$.

Lemma 2: $R(\alpha, C(\alpha)) \geq C(\alpha)$.

Proof: Again, since $\frac{C(\alpha)-W^{T} a^{T-1}(\alpha)}{C(\alpha)} \geq \alpha$, and as $C(\alpha)=W^{N} a^{N 1}(\alpha)+W^{T} a^{T 1}(\alpha)+W^{T^{*}} a^{T^{+1}}$

$$
\frac{\mathrm{W}^{\mathrm{N}} \mathrm{a}^{\mathrm{N1}}(\alpha)+\mathrm{W}^{\mathrm{T}} \mathrm{a}^{\mathrm{Tl}}(\alpha)}{\mathrm{W}^{\mathrm{N}} \mathrm{a}^{\mathrm{N} 1}(\alpha)+\mathrm{W}^{\mathrm{T}} \mathrm{a}^{\mathrm{TI}}(\alpha)+\mathrm{W}^{\mathrm{T}} \mathrm{a}^{\mathrm{TH}}(\alpha)} \geq \alpha
$$

Hence $A^{1}(\alpha)$ is feasible for Program 2. Thus, $R(\alpha, C(\alpha)) \geq C(\alpha)$ for all $\alpha$. This shows that $R(\alpha, C(\alpha))=C(\alpha)$.

Now recall that when the price definition of content requirement was used, the price itself was endogenous. With CRS, this endogenous price was defined by $\mathrm{P}^{\mathrm{US}}(\alpha)$, where

$$
\mathrm{R}\left(\alpha, \mathrm{P}^{\mathrm{US}}(\alpha)\right)=\mathrm{P}^{\mathrm{US}}(\alpha)
$$

for $\alpha \in\left[\alpha_{1}, \alpha_{3}\right]$. Thus in this region $\mathrm{P}^{\mathrm{US}}(\alpha)=\mathrm{C}(\alpha)$.

For $\alpha<\alpha_{1}$, the constraint on content requirement is not binding and the U.S. price equals the world price. For $\alpha>\alpha_{3}$, the FTA is ignored and $\mathrm{P}^{\mathrm{US}}$ equals the tariff inclusive world price under both definitions.

Thus, Lemmas 1 and 2 show that when the endogeneity of price is taken into account, and all factors are variable with CRS, as would be expected in the long run, both price and cost 
definitions of content are equivalent! This gives us Proposition 1.

Proposition 1: In the long run, with CRS, specifying rules of origin on a price or cost basis is equivalent.

How then can specifying the definition of origin on a price or cost basis matter? We show next that even if price is endogenous, if capacity constraints exist, it can matter which definition of origin is used.

Assume that Mexican capacity is fixed at $\overline{\mathrm{T}}$. Output levels up to $\overline{\mathrm{T}}$ can be produced at unit cost $\mathrm{C}(\alpha)$ or $\mathrm{R}\left(\mathrm{P}^{\mathrm{US}}, \alpha\right)$ depending on the restriction. Output levels in excess of $\overline{\mathrm{T}}$ cannot be produced at costs below $\mathrm{P}^{\mathrm{W}}(1+\mathrm{t})$. In this case, assuming $\overline{\mathrm{T}}$ is insufficient to meet U.S. demand, the U.S. price is unaffected by the FTA and remains at $P^{\mathrm{w}}(1+\mathrm{t})$. The cost in Mexico under a cost based rule is $C(\alpha)$, while the Mexican price, assuming no Mexican tariffs, is $P^{w}$. All Mexican consumption is met by imports and Mexican producers earn quasi-rents of $P^{w}(1+t)$ $C(\alpha)$ per unit in the short run in the event of a cost based rule.

However, if the rule is price-based, they will earn more. The logic is obvious. Recall that Mexican costs are $R\left(\alpha, P^{\mathrm{W}}(1+t)\right)$ for output up to $\overline{\mathrm{T}}$. Also recall that $\mathrm{R}(\alpha, \mathrm{C}(\alpha))=\mathrm{C}(\alpha)$.

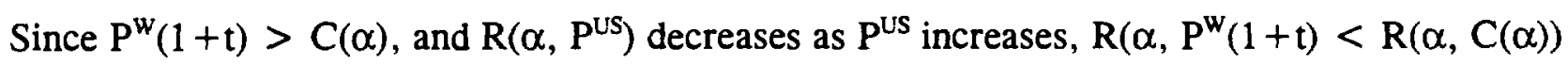
$=C(\alpha)$. Thus, in the short run, the quasi-rents earned are $P^{\mathrm{w}}(1+t)-R\left(\alpha, P^{U S}\right)$ which are in excess of $P^{\mathrm{W}}(1+t)-C(\alpha)$. Hence, Mexican producers will lobby for a price-based definition over a cost-based one in the interests of short run profits. This gives us Proposition 2.

Proposition 2: In the presence of capacity constraints, Mexican producers will prefer a pricebased definition of origin to a cost-based one.

We now turn to the effects of imperfect competition. 


\section{FOREIGN MONOPOLY IN THE PRODUCT MARKET}

We now turn to the effects of rules of origin when there is a foreign monopoly in the final product. Here our work is related to that of Hollander (1987). Hollander looked at the effect of content protection in a model where a continuum of domestic and foreign inputs is used to make the final good. However his work assumes CRS as well as fixed coefficients in production and focuses on the price based definition. He shows that even though the firm's production costs are increased by the content requirement, it could reduce the price charged and thus increase domestic welfare if the content requirement were in terms of a minimum share of the value of domestic inputs used relative to the value of sales. This could not arise if the restriction were in terms of a maximum value share on foreign input used relative to sales ${ }^{21}$.

We ask a similar question, but look at both cost- and price-based restrictions. We also step away from his restrictive assumptions on technology. In addition, since we are looking at the effects of an FTA, the problem is different. We first show that a more restrictive requirement for origin must reduce output if domestic and foreign inputs are perfect substitutes and a cost based definition is used. This result is independent of the CRS assumption. We then provide a simple proof of his result under CRS, assuming the domestic and imported inputs are perfect substitutes, but without requiring the assumption of fixed coefficients.

${ }^{21}$ With CRS this is equivalent to specifying a minimum share of the value of domestic unit input requirements relative to price. 


\subsection{A Cost Based Definition:}

Assume that a FTA is negotiated with the foreign country in which the monopolist produces, and that the partner country constitutes his market. Also assume that we are considering the short run where some input is fixed. Let $\mathrm{L}^{\mathrm{N}}$ and $\mathrm{L}^{\mathrm{T}}$ be the inputs used in production from the FTA and $\mathrm{L}^{\mathrm{T}^{*}}$ be the input used from outside the FTA. Further, let $\mathrm{L}^{\mathrm{T}}$ be fixed at $\overline{\mathrm{L}}^{\mathrm{T}}$ in the short run. Let $\mathrm{W}^{\mathrm{N}}, \mathrm{W}^{\mathrm{T}}, \mathrm{W}^{\mathrm{T}^{*}}$ be the fixed prices of these inputs. The monopolist's problem is then to choose $\mathrm{L}^{\mathrm{T}^{*}}$ and $\mathrm{L}^{\mathrm{N}}$ to minimize costs, for each output level $\mathbf{x}$, and then to choose $\mathrm{x}$ to maximize profits in the usual manner.

Note that due to the existence of fixed factors of production, costs are not constant even if the production function is CRS. Also, since output decisions are made on the basis of marginal costs, if marginal costs shift upwards (downwards) output falls (rises). Thus, we focus first on the effects of a ROO on marginal costs.

Consider the effect of a restriction on the minimum share of FTA costs relative to total costs. This problem is set up and analyzed in Section A.3 of the Appendix. $R(\alpha, x)$ is the resulting value function. It corresponds to the restricted total cost function. Hence, $R_{x}($.$) gives$ marginal costs and $R_{x \alpha}($.$) gives the effect of an increase in \alpha$ on marginal costs. Note that $R_{\alpha}($. is nonnegative. If the restriction is not binding, $R(\alpha, x)=C(x)$. In this case the monopolist is necessarily better off accepting the restriction. As $\alpha$ rises the restriction becomes binding but still remains worth accepting it. For very high levels of $\alpha$, it may be worth ignoring it and paying the required tariff. The key point to note is that $\mu$, when the domestic and imported inputs are perfect substitutes as derived in A.3 of the Appendix, is independent of $x$. Hence, $\mathrm{R}_{\mathrm{x} \alpha}=\mu \mathrm{R}_{\mathrm{x}}(\cdot)>0$. Thus, making this kind of restriction more binding raises marginal cost, 
thereby reducing output. This result obviously carries over with CRS, as marginal costs rise as the constraint becomes more binding in that case. In addition, requiring imported inputs to be less than a given share of costs must have the same effects as that of requiring domestic inputs to be more than a given share of costs since the two constraints are equivalent. This gives Proposition 3.

Proposition 3: If a domestic input is a perfect substitute for the imported input, and there is a foreign monopolist, making a binding cost-based definition of origin more restrictive reduces output.

This proposition does not mean that a FTA must reduce the output of such a monopolist. Recall that the FTA also eliminates tariffs on the final good, which tends to reduce price charged and raise output. This effect predominates if the restriction is not too severe. The effect on welfare of an FTA is more difficult. Even if output rises under the FTA, welfare need not. For welfare to rise, the gain in consumer surplus from the reduction in price due to the increase in output must exceed the loss in tariff revenue. Thisnet gain is not ensured even if marginal costs of production are not raised by the FTA.

\subsection{A Price Based Definition:}

What about a definition of content which is price based? Here we return to assuming that there are CRS. We analyze the problem in three stages. First we derive the restricted unit cost function. Then we derive the profit-maximizing output, given these costs, assuming that the restriction is accepted. Finally, we look at the choice of accepting the restriction. 
The restricted unit cost function is derived in A.4 in the Appendix. It will depend on price since unit input use is required to be at least a given fraction, $\alpha$, of the price ${ }^{22}$. Also, the restricted unit cost function will increases with price as this makes the constraint harder to meet $^{23}$. The value function for this problem is denoted by $\mathrm{R}(\alpha, \mathrm{P})$. Note that, as expected, increasing the price raises restricted unit costs and that making the requirement more restrictive raises restricted unit costs.

At the previous stage, the monopolist must choose output to maximize profits. His problem is:

$$
\text { Maximize } \pi(x ; \alpha)=P(x) x-R(P(x), \alpha) x .
$$

Since price affects unit cost, we can no longer argue that if unit costs (which equals marginal costs) rise as $\alpha$ rises, output must fall. The two stages do not separate as easily. However, there is a simple reason why this form of the restriction could lead to a reduction in price and increase in output. By increasing output and reducing price the producer can make the constraint on content less binding and he chooses to do so if the restriction is not too severe. The derivative of this profit function is given by:

$$
\Pi_{x}(x, \alpha)=P_{x}(x) x+P(x)-R_{P}(P(x), \alpha) P_{x}(x) x-R(P(x), \alpha) .
$$

Since $R_{P}(P(x), \alpha)=\alpha \mu \geq 0$ from Section A.4 in the Appendix, and $P_{x}(x)<0$, the

${ }^{2}$ This is equivalent to total input use being at least a given fraction of sales due to the assumption of CRS.

${ }^{23}$ Compare this problem to that in A.2 of the Appendix. In A.2, a maximum value share relative to price of imported unit input requirements was the constraint. In this case, an increase in price reduced the restricted cost function. In the problem specified in A.4, in contrast, an increase in price raises restricted unit costs. This points to the importance of the specification of content with a price based definition. With a cost-based definition, this issue does not arise. 
firm's marginal costs are lower than the unit costs, because raising output relaxes the constraint on value added! This is the heart of why output can rise even when unit costs rise due to the restriction.

It is easiest to illustrate what is going on when $T$ and $T^{*}$ are perfect substitutes. In this case the profit function under the content restriction is not differentiable everywhere. If $\mathrm{T}$ (or $\mathrm{N}$ ), and $\mathrm{T}^{*}$ are perfect substitutes, then $\mu$ is independent of $\alpha$ and $\mathrm{P}$, so that $\mathrm{R}_{\mathrm{P \alpha}}=\mu$. However, this means that at the point where the restriction is just binding, where the restricted profit function becomes identical with the unrestricted one, their derivatives are different. The slope of the restricted profit function (from below) exceeds that of the unrestricted one, although it lies weakly below it everywhere. It is at this point that the profit function is non differentiable.

The point at which the restriction becomes binding depends on the level of $\alpha$. For every $\alpha$ there exists a $\mathrm{P}(\alpha)$ such that the constraint is binding for $\mathrm{P}>\mathrm{P}(\alpha)$ and is not binding otherwise. This is because reducing P satisfies the constraint. $P(\alpha)$ is of course decreasing in $\alpha$. Corresponding to this just-binding level of price, there is an output level $x(\alpha)$ such that $P(x(\alpha))$ $=\mathrm{P}(\alpha)$. The constraint is binding if $\mathrm{x}<\mathrm{x}(\alpha)$ and not binding otherwise. Thus, the restricted profit function becomes identical with the unrestricted one for $x \geq x(\alpha)$. It lies below it otherwise and has a greater slope, coming from below, than the unrestricted profit function at the point where they intersect. Also, $x(\alpha)$ is increasing in $\alpha$.

Thus, there are only three possibilities, depicted in Figure 3. (1) At $x(\alpha)$ the unrestricted profit function is upward sloping. In this event so is the restricted profit function coming from below since it must be steeper. This occurs for values of $\alpha<\alpha_{1}$, where $\alpha_{1}$ corresponds to the share of FTA inputs under free trade and no content requirements. In this case the content 
restriction is not restrictive. (2) At $x(\alpha)$ the unrestricted profit function is weakly downward sloping but the restricted one is upward sloping coming from below. In this case the monopolist chooses to price to make the constraint just binding, that is at $P(\alpha)$. This must occur for $\alpha$ close to but greater than $\alpha_{1}$ since in this case the restricted profit function is upward sloping at the point the constraint is just binding. Say this occurs for $\alpha$ in $\left[\alpha_{1}, \alpha_{2}\right]$. (3) At $x(\alpha)$ the unrestricted profit function is downward sloping and so is the restricted one coming from below. In this case the monopolist chooses to produce less than $x(\alpha)$. Say this occurs for $\alpha$ in $\left(\alpha_{2}, 1\right]$. In both (2) and (3) the constraint is binding. In all of Case (2), increasing $\alpha$ raises output and reduces price. ${ }^{24}$

What then is the likely path of output under the FTA as the restriction on domestic input use becomes more severe? When the restriction is not binding, costs are unaffected, but as there is no tariff, output is higher than if there was no FTA. As the severity of the restriction increases, output rises initially and then could fall.

As profits always fall as the restriction becomes more severe, at some stage, the profit from accepting the restriction and being exempt from the tariff will yield the same profits as ignoring it. At this point the monopolist will decide to ignore the restriction and output will revert to the pre FTA levels.

What does this imply for the effect of such restrictions on welfare and the use of domestic and foreign inputs? First consider welfare. If the restriction is not too severe, output can rise above the pre-FTA level. This effect raises consumer surplus, a part of welfare.

\footnotetext{
${ }^{24}$ Note that without further restrictions on the problem we can only say that for $\alpha$ above but close to $\alpha_{1}$ output must rise as $\alpha$ does. As $\alpha$ rises further we could switch between cases (2) and (3).
} 
However, tariff revenue is lost, which tends to decrease welfare relative to the status quo before the FTA. Since the decrease in price is likely to be less than the decrease in costs due to the removal of the tariff, the latter effect is likely to dominate initially. As the rule of origin becomes binding, output rises and the effect on consumer surplus could dominate, raising welfare due to the FTA. As the restriction becomes even more binding, output could fall reducing welfare. Finally, the profits that can be obtained by accepting the content rule fall below those from accepting the tariff and welfare goes back to the pre-FTA level. This occurs at $\alpha=\alpha_{3}$.

There are two forces at work on the use of domestic inputs. First the content rule tends to distorts input use towards FTA inputs ${ }^{25}$. Second, as output changes, so does domestic input use in the same direction. Hence, the net effects are ambiguous.

It is easy to see that if the restriction on content is specified as a maximum share of nonFTA inputs as a fraction of sales, or equivalently as a maximum share on the value of non-FTA unit costs relative to price, there would be no such incentive to reduce price. In this case raising price, not reducing it, makes the constraint less binding so that a restriction set at close to freetrade levels will not raise output. We do not work through the details here, leaving them as an exercise for the interested reader.

The main conclusion to be drawn from this section is that with imperfect competition, there is even more reason to be concerned with the form of ROOs. Even forms that are equivalent under perfect competition can have quite different effects in the presence of market

${ }^{25}$ However, since all FTA inputs are so affected this need not necessarily raise the use of each domestic input. 
imperfections. 


\section{CONCLUDNG REMARKS}

In this paper we have just begun to look at how ROOs and different definitions of them can have very different effects; much remains to be done. An area we did not touch upon deals with the effects of FTA's and the accompanying ROOs on intermediate goods markets when there is market power in these markets. Here Krishna and Itoh (1986) might provide a starting point. In addition, we had little to say about non content-based definitions of origin and the effects of multiple layers of requirements as often occurs in the real world. Perhaps the most important issue we treat in a very simple manner is the effects of FTA's on Foreign Direct Investment (FDI). In contrast to content requirements on imports, which tend to lead to FDI in the importing country in order to evade the content requirement on imports, ROO's tend to lead to FDI in the lower cost country in the FTA, as this provides access to the FTA market at a lower cost to the investor. Such concerns are common in discussions dealing with NAFTA, and need further study. Nor have the implications of different ways of defining origin been explored in this context. The work begun here suggests that such issues might be well worth addressing. 


\section{References}

Beghin, John C., and C. A. Knox Lovell, "Trade and Efficiency Effects of Domestic Content Protection: The Australian Tobacco and Cigarette Industries," Mimeo 1992. Forthcoming in the Review of Economics and Statistics.

Corden, W. M., The Theory of Protection, London: Allen and Unwin, 1971.

De-Silanes, Florencio Lopez, James R. Markusen and Thomas F. Rutherford, "Anti-Competitive and Rent Styling Aspects of Domestic-Content Provisions in Regional Trading Blocks," Mimeo 1993.

Grossman, Gene M., "The Theory of Domestic Content Protection and Preference". Quarterly Journal of Economics, 1981, Vol. 96, No. 4. November, pp. 583-603.

Herin, Jan, 1986, "Rules of Origin and Differences between Tariff Levels in EFTA and in the EC," EFTA Occasional Paper No. 13, February, Geneva.

Hollander, Abraham, "Content Protection and Transnational Monopoly, " Journal of International Economics, 1987, Vol. 23, pp. 283-97.

Johnson, H.G., Aspects of the Theory of Tariffs, London: Allen and Unwin, 1971. 
Krishna, Kala and M. Itoh (1986) "Content Protection and Oligopolistic Interactions," Review of Economic Studies, January, 1988, LV, 107-125.

Krishna, Kala and L. H. Tan, "Transferability Versus Non Transferability: What is the Difference?", Mimeo 1993.

Krueger, Anne O. (1992) "Free Trade Agreements as Protectionist Devices: Rules of Origin. Forthcoming in Festschrift in honor of John Chipman's 65th Birthday.

McCulloch, R. and H. G. Johnson, "A Note on Proportionally Distributed Quotas," American Economic Review, 1973, 63, No. 4, pp. 726-32.

Mussa, M., "The Economics of Content Protection," National Bureau of Economic Research, 1984, Working Paper No. 1457.

Palmeter, N. David, "Rules of Origin in a Western Hemisphere Free Trade Agreement, " Mimeo 1993.

Steele, Keith and Daniel Moulis, "Country of Origin: The Australian Experience," Edwin Vermulst, Paul Waer and Jacques Bourgeois (Eds.), Rules of Origin in International Trade: A Comparative Study. Ann Arbor: University of Michigan Press, 1994. 


\section{Appendix}

\section{A.1: A Restriction on the Share of FTA Costs Relative to Total Costs:}

The Lagrangian for the problem of minimizing cost subject to a minimum share, $\alpha$, of costs coming from within the FTA, is given by:

$$
\begin{aligned}
& \mathscr{L}=W^{N} a^{N}+W^{T} a^{T}+W^{T^{*}} a^{T^{\bullet}}-\phi\left[W^{N} a^{N}+W^{T} a^{T}-\alpha\left(W^{N} a^{N}+W^{T} a^{T}\right.\right. \\
& \left.\left.+\mathrm{W}^{\mathrm{T}^{*}} \mathrm{a}^{\mathrm{T}}\right)\right]-\mu\left[\mathrm{F}\left(\mathrm{a}^{\mathrm{N}}, \mathrm{a}^{\mathrm{T}}, \mathrm{a}^{\mathrm{T}}\right)-1\right] \\
& \frac{\partial \mathscr{L}}{\partial \mathrm{a}^{\mathrm{N}}}=\mathrm{W}^{\mathrm{N}}-\phi(1-\alpha) \mathrm{W}^{\mathrm{N}}-\mu \mathrm{F}_{\mathrm{a}^{N}}(\cdot)=0 \\
& \Rightarrow \mathrm{W}^{\mathrm{N}}(1-\phi(1-\alpha))=\mu \mathrm{F}_{\mathrm{a}^{\mathrm{N}}}(\cdot) \\
& \frac{\partial \mathscr{L}}{\partial \mathrm{a}^{\mathrm{T}}}=\mathrm{W}^{\mathrm{T}}-\phi(1-\alpha) \mathrm{W}^{\mathrm{T}}-\mu \mathrm{F}_{\mathrm{a}^{\mathrm{T}}}(\cdot)=0 \\
& \Rightarrow \mathrm{W}^{\mathrm{T}}(1-\phi(1-\alpha))=\mu \mathrm{F}_{\mathrm{a}^{\mathrm{T}}}(\cdot) \\
& \frac{\partial \mathscr{L}}{\partial \mathrm{a}^{\mathrm{T}^{*}}}=\mathrm{W}^{\mathrm{T}^{*}}+\phi \alpha \mathrm{W}^{\mathrm{T}^{*}}-\mu \mathrm{F}_{\mathrm{a}^{\mathrm{T}^{*}}} \cdot(\cdot)=0 \\
& =>(1+\phi \alpha) \mathrm{W}^{\mathrm{T}^{*}}=\mu \mathrm{F}_{\mathrm{a}^{\mathrm{T}^{*}}}(\cdot) \\
& \frac{\partial \mathscr{L}}{\partial \phi}=\left[\mathrm{W}^{\mathrm{N}} \mathrm{a}^{\mathrm{N}}+\mathrm{W}^{\mathrm{T}} \mathrm{a}^{\mathrm{T}}-\alpha\left(\mathrm{W}^{\mathrm{N}} \mathrm{a}^{\mathrm{N}}+\mathrm{W}^{\mathrm{T}} \mathrm{a}^{\mathrm{T}}+\mathrm{W}^{\mathrm{T}} \mathrm{a}^{\mathrm{T}}\right] \geq 0\right. \\
& {\left[W^{N} a^{N}+W^{T} a^{T}-\alpha\left(W^{N} a^{N}+W^{T} a^{T}+W^{T} a^{T}\right] \phi=0\right.} \\
& \frac{\partial \mathscr{L}}{\partial \mu}=\mathrm{F}\left(\mathrm{a}^{\mathrm{N}}, \mathrm{a}^{\mathrm{T}}, \mathrm{a}^{\mathrm{T}}\right)-1=\dot{0}
\end{aligned}
$$

Note that the first-order conditions with respect to $\mathrm{a}^{\mathrm{T}}, \mathrm{a}^{\mathrm{N}}$, and $\mathrm{a}^{\mathrm{T}}$ imply that the value- 
added constraint does not affect the ratio of the marginal products of $\mathrm{N}$ and $\mathrm{T}$. Let $\mathrm{R}\left(\mathrm{W}^{\mathrm{N}}, \mathrm{W}^{\mathrm{T}}, \mathrm{W}^{\mathrm{T}}, \alpha\right)$ be the value function for this problem. By the envelope theorem:

$$
\begin{gathered}
R_{\mathrm{w}^{\mathrm{N}}}=\mathrm{a}^{\mathrm{N}}(1-\phi(1-\alpha)) \\
\mathrm{R}_{\mathrm{w}^{\mathrm{T}}}(\cdot)=\mathrm{a}^{\mathrm{T}}(1-\phi(1-\alpha)) \\
\mathrm{R}_{\mathrm{w}^{r^{*}}}=\mathrm{a}^{\mathrm{T}}(1+\phi \alpha) \\
\mathrm{R}_{\alpha}=\phi \mathrm{R}(\cdot) \\
\mathrm{R}_{\alpha \alpha}=\phi_{\alpha} \mathrm{R}+\phi^{2} \mathrm{R}(\cdot)=\mathrm{R}\left(\phi_{\alpha}+\phi^{2}\right) \\
\mathrm{R}(\cdot) \text { is } \mathrm{HD} 1 \text { in } \mathrm{W}^{\mathrm{N}}, \mathrm{W}^{\mathrm{T}}, \mathrm{W}^{\mathrm{T}} .
\end{gathered}
$$

From interpreting the first-order conditions it is apparent that the value-added constraint acts like a tax of $\phi \alpha W^{T^{*}}$ on the use of $\mathrm{T}^{*}$ and a subsidy of $\phi(1-\alpha) W^{N}$ on the use of $\mathrm{N}$ and of $\phi(1-\alpha) W^{T}$ on the use of T. In this way the FTA acts to export protection.

\section{A.2 A Restriction on the Value of Non FTA inputs as a Share of Price:}

The problem in this case is to:

$$
\text { Minimize } W^{N} a^{N}+W^{T} a^{T}+W^{T^{*}} a^{T^{*}}
$$


subject to:

$$
\begin{aligned}
& \frac{P^{U S}-W^{T^{*}} a^{T *}}{P^{U S}} \geq \alpha \\
& F\left(a^{N}, a^{T}, a^{T *}\right) \geq 1 .
\end{aligned}
$$

The Lagrangian for this minimization problem is given by:

$$
\begin{aligned}
& \mathscr{L}\left(\mathrm{a}^{\mathrm{N}}, \mathrm{a}^{\mathrm{T}}, \mathrm{a}^{\mathrm{T}}, \lambda, \mu\right)=\mathrm{W}^{\mathrm{N}} \mathrm{a}^{\mathrm{N}}+\mathrm{W}^{\mathrm{T}} \mathrm{a}^{\mathrm{T}}+\mathrm{W}^{\mathrm{T}} \mathrm{a}^{\mathrm{T}} \\
& -\lambda\left[\mathrm{Pus}^{\mathrm{u}}-\mathrm{W}^{\mathrm{T}} \mathrm{a}^{\mathrm{T}}-\alpha \mathrm{P}^{\mathrm{US}}\right]-\mu\left[\mathrm{F}\left(\mathrm{a}^{\mathrm{N}}, \mathrm{a}^{\mathrm{T}}, \mathrm{a}^{\mathrm{T}^{*}}\right)-1\right]
\end{aligned}
$$

The first-order conditions are given by:

$$
\begin{gathered}
\frac{\partial \mathscr{L}}{\partial \mathrm{a}^{N}}=\mathrm{W}^{\mathrm{N}}-\mu \mathrm{F}_{\mathrm{a}^{N}}=0 \\
\frac{\partial \mathscr{L}}{\partial \mathrm{a}^{\mathrm{T}}}=\mathrm{W}^{\mathrm{T}}-\mu \mathrm{F}_{\mathrm{a}^{\mathrm{T}}}=0 \\
\frac{\partial \mathscr{L}}{\partial \mathrm{a}^{\mathrm{T}^{*}}}=\mathrm{W}^{\mathrm{T}^{*}}(1+\lambda)-\mu \mathrm{F}_{\mathrm{a}^{*}}=0
\end{gathered}
$$

assuming that all inputs are essential to production.

$$
\begin{aligned}
& \frac{\partial \mathscr{L}}{\partial \lambda}=\mathrm{P}^{U S}-\mathrm{W}^{\mathrm{T}^{*}} \mathrm{a}^{\mathrm{T}}-\alpha \mathrm{P}^{\mathrm{US}} \geq 0
\end{aligned}
$$

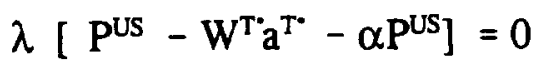




$$
\frac{\partial \mathscr{L}}{\partial \mu}=\mathrm{F}\left(\mathrm{a}^{\mathrm{N}}, \mathbf{a}^{\mathrm{T}}, \mathbf{a}^{\mathrm{T}}\right)-1=0
$$

Note that the complementary slackness condition associated with the value-added constraint above is explicitly given since the constraint on value added need not be binding.

Note also that if $\lambda \neq 0$ then the value added constraint is binding, and the first-order condition with respect to $\lambda$ holds as an equality so that $\mathrm{a}^{\mathrm{T}^{*}}=\frac{\mathrm{P}^{\mathrm{US}}(1-\alpha)}{\mathrm{W}^{\mathrm{T}}}$. This leaves the remaining four first-order conditions to solve for $\mathrm{a}^{\mathrm{T}}, \mathrm{a}^{\mathrm{N}}, \lambda$ and $\mu$. The value function obtained by substitution for these solution values of the choice variables is what we called $\mathrm{R}\left(\mathrm{W}^{\mathrm{N}}, \mathrm{W}^{\mathrm{T}}, \mathrm{W}^{\mathrm{T}}, \alpha, \mathrm{P}^{\mathrm{US}}\right)$ earlier. Note that the first-order conditions with respect to $\mathrm{a}^{\mathrm{N}}$ and $a^{T}$ show that whatever is $\alpha$, the choice of the nontraded $(\mathrm{N})$ and FTA produced $(\mathrm{T})$ input will not be distorted relative to each other by the restriction on value added. The ratios of marginal productivity are still equated to factor price ratios.

Also note that:

$$
\begin{aligned}
& \mathbf{R}_{\mathrm{W}^{\mathrm{m}}}(.)=\mathrm{a}^{\mathrm{N}}(\cdot) \\
& \mathbf{R}_{\mathrm{W}^{\mathrm{r}}}(.)=\mathbf{a}^{\mathrm{T}}(\text { ()) } \\
& R_{W^{\top}}(.)=\mathrm{a}^{\mathrm{T}^{*}}(\cdot)(1+\lambda)
\end{aligned}
$$

It is clear from the three first-order conditions with respect to input use that the restriction works to reduce the use of the input from the rest of the world relative to the unconstrained solution. It acts like a tariff of $\lambda \mathrm{W}^{\mathrm{T}}$ on the import of the input from the rest of 
the world. Thus, $\lambda$ can be interpreted as the ad valorem tariff equivalent. This is one way that the FTA "exports protection".

Finally, note that if $a^{T}$ and $a^{T^{*}}$ are perfect substitutes for each other, then from the first-order conditions with respect to $\mathrm{a}^{\mathrm{T}}$ and $\mathrm{a}^{\mathrm{T} *}$ we get:

$$
\frac{\mathrm{W}^{\mathrm{T}}}{\mathrm{W}^{\mathrm{T}^{\circ}}(1+\lambda)}=1
$$

So that $\lambda=\frac{\mathrm{W}^{\mathrm{T}}-\mathrm{W}^{\mathrm{T}}}{\mathrm{W}^{\mathrm{T}}}$ and is $\underline{\text { independent }}$ of $\alpha$ and $\mathrm{P}^{\mathrm{US}}$. In this special case $\mathrm{R}_{\alpha \alpha}()=$. and $R($.$) is linear in \alpha$.

A.3 A Restriction on the Minimum Share of FTA Costs Relative to Total Costs Without CRS:

As $\mathrm{L}^{\mathrm{N}}$ and $\mathrm{L}^{\mathrm{T}}$ are assumed to come from within the FTA the problem is to:

Minimize $W^{N} L^{N}+W^{T} \bar{L}^{T}+W^{* T} L^{* T}$ subject to

$$
\frac{W^{N} L^{N}+W^{T} L^{T}}{W^{N} L^{N}+W^{T} L^{T}+W^{\cdot T} L^{\cdot T}} \geq \alpha
$$


and

$$
\mathrm{F}\left(\mathrm{L}^{\mathrm{N}}, \overline{\mathrm{L}}^{\mathrm{T}}, \mathrm{L}^{* \mathrm{~T}}\right)=\mathrm{x}
$$

The value function for this problem is denoted by $R\left(W^{N}, W^{T *}, W^{T}, \bar{L}^{T}, \alpha, x\right)$ which is the restricted total cost function.

The Lagrangian for this problem is given by:

$$
\begin{gathered}
\mathscr{L}\left(\mathrm{L}^{\mathrm{N}}, \mathrm{L}^{\mathrm{T}}, \lambda, \mu\right)=\mathrm{W}^{\mathrm{N}} \mathrm{L}^{\mathrm{N}}+\mathrm{W}^{\mathrm{T}} \overline{\mathrm{L}}^{\mathrm{T}}+\mathrm{W}^{\mathrm{T}} \mathrm{L}^{\mathrm{T}} \cdot \\
-\lambda\left[\mathrm{F}\left(\mathrm{L}^{\mathrm{N}}, \overline{\mathrm{L}}^{\mathrm{T}}, \mathrm{L}^{\mathrm{T}}\right)-\mathrm{x}\right] \\
-\mu\left[\mathrm{W}^{\mathrm{N}} \mathrm{L}^{\mathrm{N}}+\mathrm{W}^{\mathrm{T}} \overline{\mathrm{L}}^{\mathrm{T}}-\alpha\left(\mathrm{W}^{\mathrm{N}} \mathrm{L}^{\mathrm{N}}+\mathrm{W}^{\mathrm{T}} \overline{\mathrm{L}}^{\mathrm{T}}+\mathrm{W}^{\mathrm{T}} \mathrm{L}^{\mathrm{T}}\right)\right]
\end{gathered}
$$

The first-order conditions are:

$$
\begin{gathered}
\frac{\partial \mathscr{L}(\cdot)}{\partial \mathrm{L}^{\mathrm{N}}}=\mathrm{W}^{\mathrm{N}}(1-\mu(1-\alpha))-\lambda \mathrm{F}_{\mathrm{L}^{\mathrm{N}}}(\cdot)=0 \\
\frac{\partial \mathscr{L}(\cdot)}{\partial \mathrm{L}^{\mathrm{T}}}=\mathrm{W}^{\mathrm{T}}(1+\mu \alpha)-\lambda \mathrm{F}_{\mathrm{T} \cdot}(\cdot)=0 \\
\frac{\partial \mathscr{L}(\cdot)}{\partial \lambda}=-\left[\mathrm{F}\left(\mathrm{L}^{\mathrm{N}}, \overline{\mathrm{L}}^{\mathrm{T}}, \mathrm{L}^{\mathrm{T}}\right)-\mathrm{x}\right]=0 \\
\frac{\partial \mathscr{L}(\cdot)}{\partial \mu}=-\left[\mathrm{W}^{\mathrm{N}} \mathrm{L}^{\mathrm{N}}+\mathrm{W}^{\mathrm{T}} \overline{\mathrm{L}}^{\mathrm{T}}-\alpha\left(\mathrm{W}^{\mathrm{N}} \mathrm{L}^{\mathrm{N}}+\mathrm{W}^{\mathrm{T}} \overline{\mathrm{L}}^{\mathrm{T}}+\mathrm{W}^{\mathrm{T}} \mathrm{L}^{\mathrm{T}}\right)\right]=0
\end{gathered}
$$

Note that by the envelope theorem, $R_{\alpha}(\cdot)=\mu R(\cdot)$. Also,

$$
R_{\alpha x}(\cdot)=\mu R_{x}(\cdot)+R(\cdot) \frac{d \mu}{d x} \cdot=R_{x \alpha}(\cdot)
$$

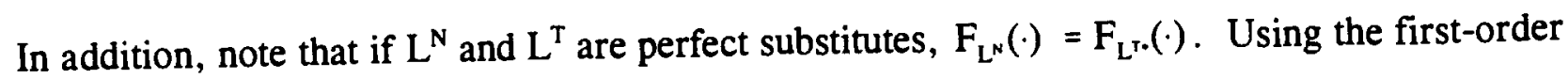
conditions with respect to $\mathrm{L}^{\mathrm{N}}$ and $\mathrm{L}^{\mathrm{T}}$ we get: 


$$
\frac{\mathrm{W}^{\mathrm{N}}}{\mathrm{W}^{\mathrm{T}^{*}}}=\frac{1+\mu \alpha}{1-\mu(1-\alpha)}
$$

This defines $\mu$ for given $\alpha, \mathrm{W}^{\mathrm{N}}, \mathrm{W}^{\mathrm{T}}$.

\section{A.4 A Restriction on the Use of Domestic Inputs as a Share of Sales With CRS:}

The problem to which the restricted unit cost function is the solution is:

Minimize $\mathrm{W}^{\mathrm{N}} \mathrm{a}^{\mathrm{N}}+\mathrm{W}^{\mathrm{T}} \mathrm{a}^{\mathrm{T}}+\mathrm{W}^{\mathrm{T}} \mathrm{a}^{\mathrm{T}}$

Subject to: $\frac{W^{N} a^{N}+W^{T} a^{T}}{P} \geq \alpha$ and

$F\left(a^{N}, a^{T}, a^{T \eta}\right)=1$

where a denotes the unit input requirement.

The Lagrangian for this problem is:

$$
\begin{gathered}
\mathscr{L}\left(\mathrm{a}^{\mathrm{N}}, \mathrm{a}^{\mathrm{T}}, \mathrm{a}^{\mathrm{T} *}, \lambda, \mu\right)=\mathrm{W}^{\mathrm{N}} \mathrm{a}^{\mathrm{N}}+\mathrm{W}^{\mathrm{T}} \mathrm{a}^{\mathrm{T}}+\mathrm{W}^{\mathrm{T}} \mathrm{a}^{\mathrm{T} *} \\
-\lambda\left[\mathrm{F}\left(\mathrm{a}^{\mathrm{N}}, \mathrm{a}^{\mathrm{T}}, \mathrm{a}^{\mathrm{T}}\right)-1\right] \\
-\mu\left[\mathrm{W}^{\mathrm{N}} \mathrm{a}^{\mathrm{N}}+\mathrm{W}^{\mathrm{T}} \mathrm{a}^{\mathrm{T}}-\alpha \mathrm{P}\right]
\end{gathered}
$$

The first-order conditions are:

Let $R(\alpha, P)$ be the value function for this problem. By the envelope theorem, $R_{P}=\alpha \mu$ 


$$
\begin{array}{ll}
> & \frac{\partial \mathscr{L}(\cdot)}{\partial \mathrm{a}^{\mathrm{N}}}=\mathrm{W}^{\mathrm{N}}(1-\mu)-\lambda \mathrm{F}_{\mathrm{a}^{\mathrm{N}}}(\cdot)=0 \\
0 . & \frac{\partial \mathscr{L}(\cdot)}{\partial \mathrm{a}^{\mathrm{T}}}=\mathrm{W}^{\mathrm{T}}(1-\mu)-\lambda \mathrm{F}_{\mathrm{a}^{\mathrm{T}}}(\cdot)=0 \\
\mathrm{~T} & \frac{\partial \mathscr{L}(\cdot)}{\partial \mathrm{a}^{\mathrm{T}}}=\mathrm{W}^{\mathrm{T} *}-\lambda \mathrm{F}_{\mathrm{a}^{\mathrm{T} \cdot}}(\cdot)=0 \\
\text { hu } & \frac{\partial \mathscr{L}(\cdot)}{\partial \lambda \cdot}=-\left[\mathrm{F}\left(\mathrm{a}^{\mathrm{N}}, \mathrm{a}^{\mathrm{T}}, \mathrm{a}^{\mathrm{T}}\right)-1\right]=0 \\
\mathrm{~s}, & \frac{\partial \mathscr{L}(\cdot)}{\partial \mu}=-\left[\mathrm{W}^{\mathrm{N}} \mathrm{a}^{\mathrm{N}}+\mathrm{W}^{\mathrm{T}} \mathrm{a}^{\mathrm{T}}-\alpha \mathrm{P}\right]=0 \\
\text { in } & \text { cr }
\end{array}
$$

ea

sing price raises restricted unit costs. $\mathrm{R}_{\alpha}=\mu \mathrm{P}$ so that making the requirement more restrictive also raises unit costs. Finally, $\mathrm{R}_{\mathrm{P} \alpha}=\mu+\alpha \mathrm{d} \mu / \mathrm{d} \alpha$. If $\mathrm{T}$ or $\mathrm{N}$, and $\mathrm{T}^{*}$ are perfect substitutes, then from the first-order conditions $\mu$ is independent of $\alpha$ as:

$$
\mu=\frac{W^{T}-W^{T *}}{W^{T}} .
$$

Hence, in this case: $\mathrm{R}_{\mathrm{P} \alpha}=\mu$. 


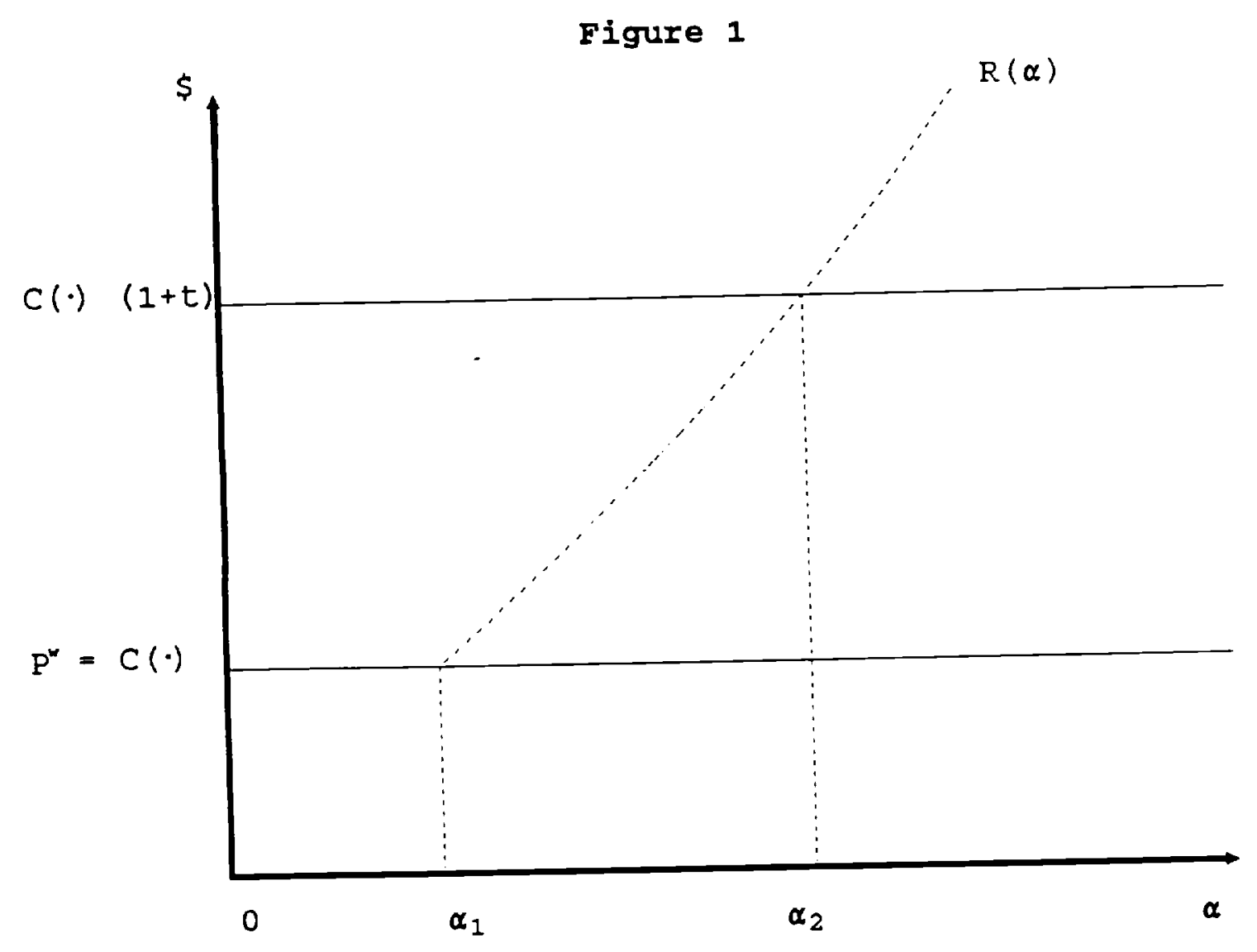

A Cost Based Roo 
Figure 2

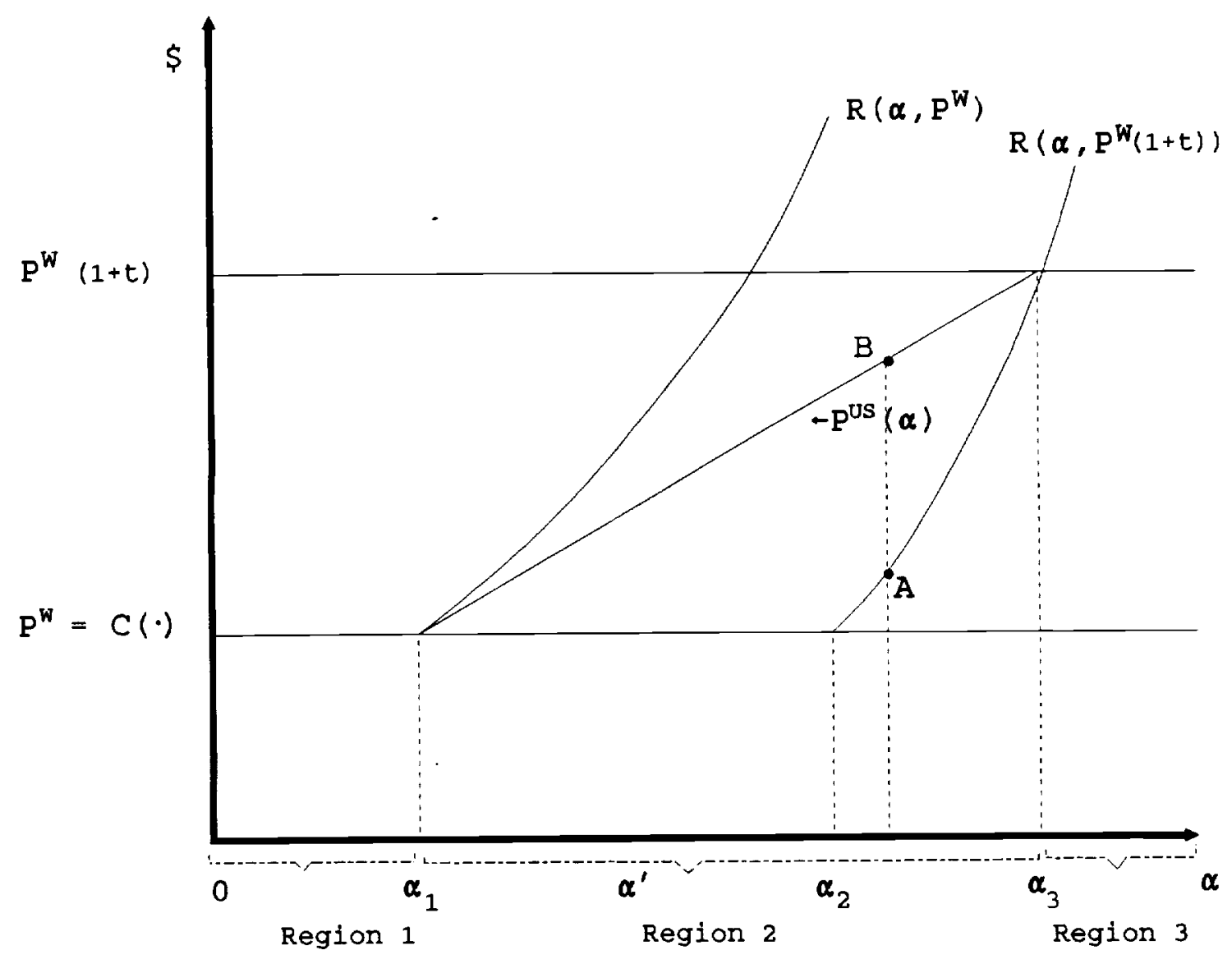

A Price Based Roo 
(a)

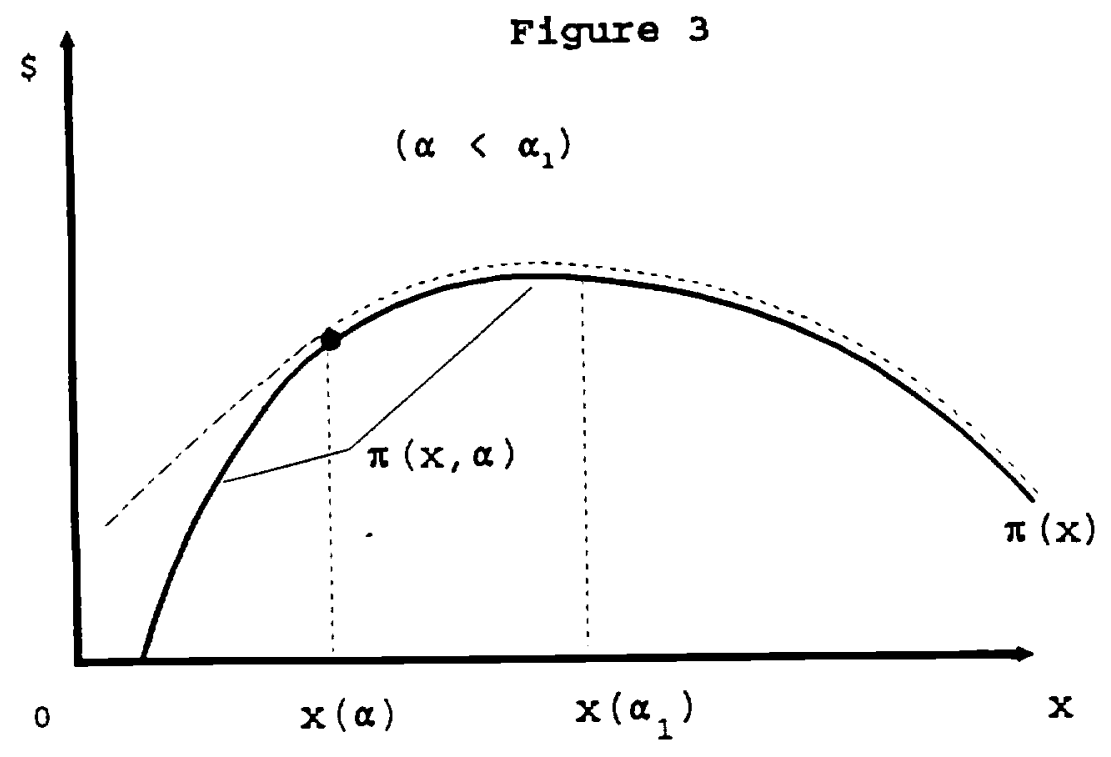

(b)

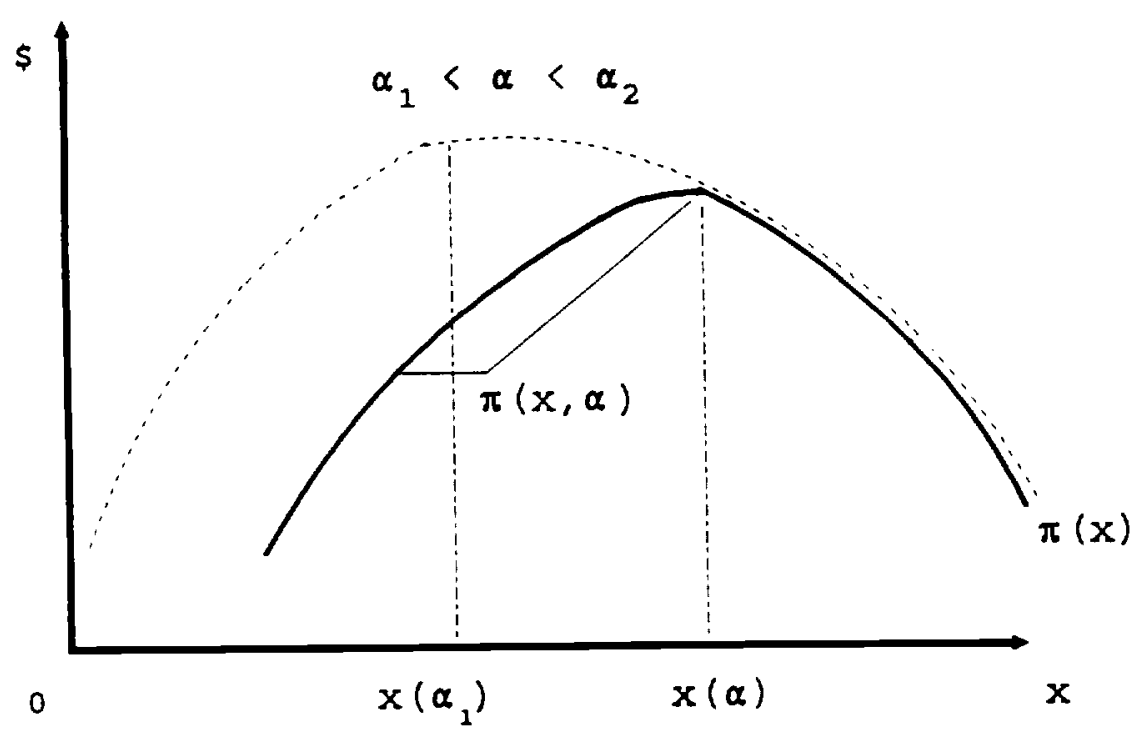

(c)

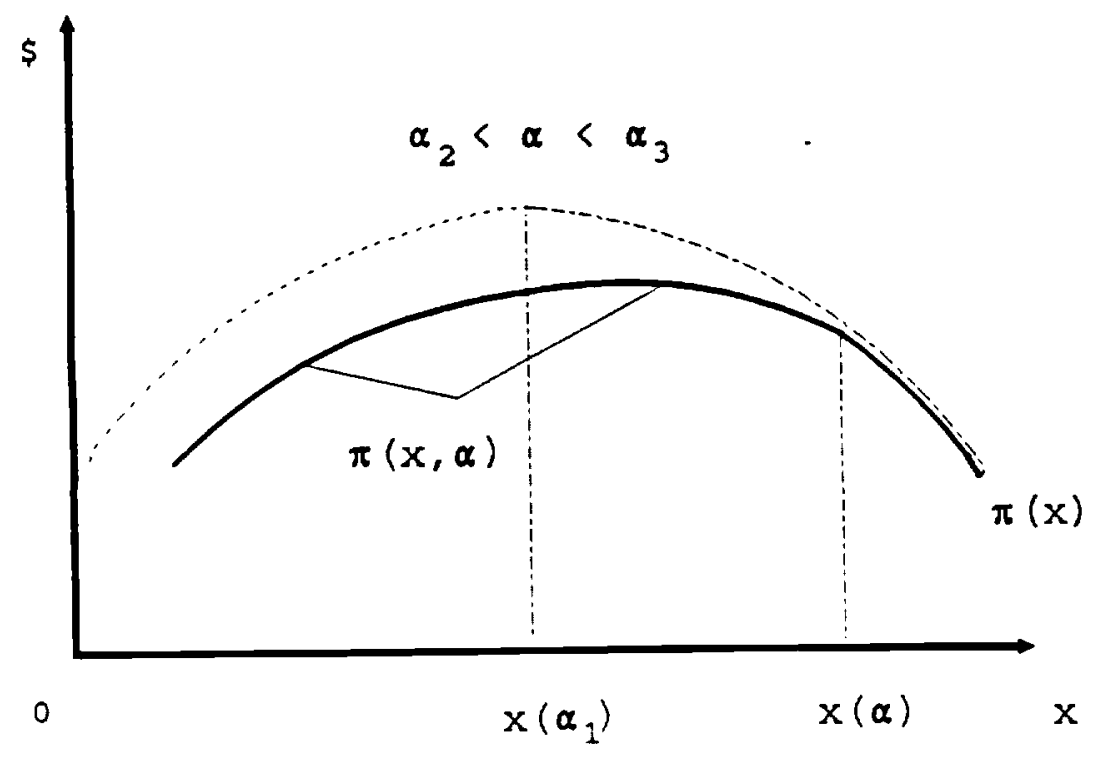

output Choice with Monopoly 